Revista de Derecho

\title{
Pluralismo jurídico posdesarrollista en la Constitución de Montecristi
}

\section{Postdevelopmental legal pluralism in the Montecristi Constitution}

\section{Yesica Álvarez Lugo}

Miembro colaborador del Instituto Hegoa-Universidad del País Vasco UPV/EHU, España yesicala3@gmail.com

ORCID: 0000-0002-2368-6880

DOI: https://doi.org/10.32719/26312484.2020.34.1

Fecha de recepción: 22 de septiembre de 2019

Fecha de aceptación: 6 de enero de 2020 


\section{RESUMEN}

Este artículo se centra en el análisis de las potencialidades de la Constitución de Montecristi para permitir el avance hacia la construcción de un tipo de pluralismo jurídico entendido en clave posdesarrollista. Los pueblos indígenas pueden considerarse como el caso paradigmático de reivindicación conjunta de pluralismo jurídico y de alternativas al desarrollo sobre la base de sus derechos territoriales. Estas reivindicaciones se encuentran inexorablemente unidas; por tal motivo, en el presente trabajo se comenzará analizando el carácter indisoluble que para determinados pueblos indígenas tiene la defensa de sus territorios con respecto a la defensa de sus propios sistemas jurídicos y de sus modos de vida en armonía con la Naturaleza. En segundo lugar, y sin perder el hilo del estudio previo, se presentará lo que se entiende por "pluralismo jurídico posdesarrollista", concepto que posteriormente se va a relacionar con el articulado vinculado con el Sumak Kawsay/Buen Vivir, derechos de la Naturaleza y el Estado plurinacional e intercultural presente en la Constitución de Montecristi. La lectura interrelacionada de este articulado será lo que nos permita sostener en un plano teórico que el texto constitucional ecuatoriano de 2008 tiene un carácter potencialmente transformador que podría servir como herramienta político-jurídica de superación de la doctrina jurídica monista y del modelo de desarrollo convencional-economicista.

Palabras Clave: pluralismo jurídico, posdesarrollo, pueblos indígenas, derechos territoriales, Constitución de Montecristi.

\section{ABSTRACT}

This article focuses on the analysis of the potentialities of the Montecristi Constitution to allow progress towards the construction of a type of legal pluralism understood in postdevelopmentalist key. Indigenous peoples can be considered as a paradigmatic case of joint vindication of legal pluralism and alternatives to development on the basis of their territorial rights. These claims are inexorably united and that is why this paper will begin by analyzing the indissoluble character that for certain indigenous peoples the defense of their territories has with respect to the defense of their own legal systems and their ways of life in harmony with Nature. Secondly, and without losing the thread of the previous study, what is understood by "postdevelopmentalist legal pluralism" will be presented, a concept that will later be related to the constitutional articles linked to the Sumak Kawsay/Buen Vivir, rights of Nature and the plurinational and intercultural State present in the Montecristi Constitution. The interrelated reading of this article will be what allows us to sustain in a theoretical plane that the Ecuadorian constitutional text of 2008 has a potentially transforming character that could serve as a political-juridical tool of overcoming the monist legal doctrine and the conventional-economicist development model.

KeYWORDs: legal pluralism, postdevelopment, indigenous peoples, territorial rights, Montecristi Constitution. 


\section{INTRODUCCIÓN}

$\mathrm{E}$ 1 estudio del pluralismo jurídico con respecto a los Derechos o sistemas jurídicos de los pueblos y nacionalidades indígenas generalmente se reduce al análisis de la administración de justicia en los casos que -desde una perspectiva de derecho estatal-identificaríamos con el ámbito del Derecho penal y el Derecho civil. No obstante, los sistemas jurídicos indígenas -como su propio nombre indica-son sistemas compuestos por un conjunto de normas, autoridades, procedimientos e instituciones que no se circunscriben únicamente a estos "ámbitos", sino que tienen que ver de una manera más amplia e integral con el gobierno de sus territorios. Hablamos, por tanto, que el derecho de los pueblos indígenas a ejercer sus propios sistemas jurídicos tiene directa relación con los derechos de autodeterminación y autogobierno que les reconocen los instrumentos tanto internacionales como regionales en materia de derechos humanos y, por supuesto, también nacionales. Por tanto, reducir el pluralismo jurídico al estudio de cómo se dirimen conflictos "penales" o "civiles" por la llamada justicia indígena es limitar la complejidad en la regulación de territorios y relaciones interpersonales a la mera administración de justicia y obviar que modos de vida alternativos al desarrollo son posibles, en parte, por la existencia de sistemas jurídicos diferentes al Derecho estatal que legitiman, regulan y mantienen modos de vida en armonía con la Naturaleza.

En el presente trabajo se parte de esta consideración para defender que los sistemas jurídicos indígenas vienen a legitimar y regular -como cualquier otro sistema jurídico - todo un modo de vida determinado en un territorio dado y el conjunto de relaciones que en este tienen lugar (relaciones intercomunitarias, en relación con la Naturaleza, actividades productivas y de consumo, etc.). Ello significa que el derecho a ejercer sus propios sistemas jurídicos está intrínsecamente relacionado con sus derechos territoriales y con el mantenimiento de sus modos de vida alternativos al modelo de desarrollo convencional-economicista. La Constitución de Montecristi y su articulado aporta esperanzas en el sentido de entender esta relación entre derechos territoriales, sistemas jurídicos indígenas y alternativas al desarrollo al haber reconocido los derechos colectivos indígenas y un tipo de pluralismo jurídico fuerte en un contexto más amplio de búsqueda del Sumak Kawsay/Buen Vivir, de reconocimiento a los derechos de la Naturaleza y de declaración del carácter intercultural y plurinacional del Estado. Ello nos lleva a sostener que la Constitución ecuatoriana de 2008 puede hacer posible la superación del modelo de desarrollo convencional y de la doctrina jurídica monista que lo avala para ir transitando hacia la construcción de un tipo de pluralismo jurídico entendido en clave posdesarrollista en el que queden legitimados los sistemas jurídicos de los pueblos y nacionalidades indígenas y sus modos de vida en armonía con la Naturaleza. 


\section{RELACIÓN INDISOLUBLE ENTRE PLURALISMO JURÍDICO, DERECHOS TERRITORIALES Y MODOS DE VIDA ALTERNATIVOS AL DESARROLLO}

El "pluralismo jurídico" es entendido generalmente -por falta de consenso en su definición- como la coexistencia en un mismo espacio político y social de dos o más sistemas jurídicos, y que puede ser tanto a nivel infraestatal como supraestatal. ${ }^{1}$ De otro lado, se entiende por "monismo jurídico" la doctrina jurídica imperante propia del modelo de Estado-nación moderno por la cual el Derecho estatal es el único posible y legítimo. ${ }^{2}$ En este sentido, los pueblos indígenas pueden ser considerados como un sujeto histórico de gran relevancia en las luchas por la defensa del pluralismo jurídico de carácter infraestatal al haber protegido sus sistemas jurídicos a lo largo del tiempo y, por tanto, en las experiencias de resistencia al monismo jurídico del Estadonación moderno. No obstante, ya que muchos de estos pueblos mantienen y reivindican modos de vida en armonía con la Naturaleza, también podríamos considerarlos como un sujeto político importante contrario al modelo de desarrollo convencionaleconomicista imperante. Y no es que partamos de una visión romántica o idealizada de los pueblos indígenas. Sabemos que hay una amplia diversidad y heterogeneidad entre dichos pueblos y nacionalidades, pero simplemente dirigimos nuestra mirada a estos pueblos debido a que algunos aún conservan "una serie de prácticas que no corresponden a la racionalidad capitalista/moderna/occidental". ${ }^{3}$ Dichas prácticas y modos de vida persisten $-\mathrm{o}$ intentan persistir- fuera del paradigma dominante que impone el discurso desarrollista y responden a otras racionalidades, a otros sistemas jurídicos y a otras prioridades de vida.

En el caso concreto de los pueblos y nacionalidades indígenas que defienden modos de vida en armonía con la Naturaleza, podemos afirmar que existe una relación indisoluble entre la defensa de sus territorios, de sus sistemas jurídicos y de sus modos de vida. Defender uno de estos elementos supone, a la par, defender los otros. Y ello

1. Boaventura de Sousa Santos, "Law: A Map of Misreading: Toward a Postmodern Conception of Law", Journal of Law and Society 14, n. ${ }^{\circ} 3$ (1987): 279-302; y Brian Z. Tamanaha, "A Non-Essentialist Version of Legal Pluralism", Journal of Law and Society 27, n. ${ }^{\circ} 2$ (2000): 296-321.

2. John Griffiths, "What is Legal Pluralism?", Legal Pluralism \& Unofficial Law 18, n. ${ }^{\circ} 24$ (1986): 1-55; Sally Engle Merry, "Legal Pluralism”, en Social Control: Aspects of Non-state Justice, ed. Stuart Henry, 13764, The International Library of Criminology and Criminal Justice (England: Dartmouth, 1994); Raquel Yrigoyen Fajardo, Pautas de Coordinación entre el Derecho Indigena y el Derecho Estatal (Ciudad de Guatemala: Fundación Myrna Mack, 1999); Antonio Carlos Wolkmer, Pluralismo jurídico: Fundamentos de una nueva cultura del Derecho (Sevilla: MAD, 2006).

3. Miriam Lang, ¿Erradicar la pobreza o empobrecer las alternativas? (Quito: Universidad Andina Simón Bolívar / Abya-Yala, 2017), 35. 
debido a que cualquier modo de vida -responda este a parámetros propios del modelo de desarrollo convencional o a sus alternativas- se regula, legitima y mantiene por un conjunto de normas, autoridades, procedimientos e instituciones; es decir, cualquier modo de vida se sostiene por un sistema jurídico que regula las actividades, relaciones y aspiraciones que pueden ser desarrolladas en un territorio y sociedad dados, así como el sistema de organización social, económico y cultural que en dicho territorio esté establecido. En este sentido, los pueblos indígenas pueden considerarse como el caso paradigmático de reivindicación conjunta de pluralismo jurídico y de alternativas al desarrollo sobre la base de sus derechos territoriales, pues dichas reivindicaciones, como se ha enunciado, se encuentran inexorablemente unidas. Así, podemos considerar que los pueblos indígenas son un ejemplo claro de: 1. pluralismo jurídico, pues su Derecho se ha seguido practicando (no de manera estática sino cambiando en el tiempo, como es lógico) en relaciones variables de armonía o conflictividad con respecto a las leyes y normas estatales; y 2. de unos modelos de desarrollo diferentes o alternativos al imperante, un modo de vida en mayor armonía con la Naturaleza y con la comunidad.

Según la Corte Interamericana de Derechos Humanos ${ }^{4}$ (Corte IDH), los derechos territoriales indígenas suponen el núcleo o el eje que posibilita el disfrute del resto de los derechos humanos de los pueblos indígenas y tribales. Esto significa que, sin el territorio, el disfrute pleno del derecho a la vida, a la autodeterminación, a la identidad, a la cultura, a la religión y a la no discriminación no es posible, y ello es así debido a la existencia de una íntima e indisoluble relación entre el derecho al territorio y a la propia supervivencia. Dada la envergadura y significación del territorio para las realidades indígenas y para el ejercicio de sus derechos, es comprensible su ahínco por reclamar su jurisdicción y defenderlo ante otros agentes -como Estados y empresas- que pretenden hacer uso de este. $\mathrm{Y}$ es que las disputas entre los diversos agentes por el control de un determinado territorio van unidas a las expectativas de gestión del mismo y de los recursos que en él se encuentran, lo que a su vez responde a una visión de modelo de organización social y económica determinada. Todo ello se traduce en un doble choque: por un lado, un choque entre modelos o formas de entender la vida, la organización social y la gestión del territorio y los recursos naturales; y, por otra parte, un choque con las leyes y la institucionalidad sobre las que descansa dicho modelo, es decir que fruto de este doble choque surge la reclamación por parte de los pueblos indígenas, no solo de un modelo de desarrollo distinto (o de

4. Corte IDH, "Sentencia de 17 de junio de 2005 (Fondo, Reparaciones y Costas)", Caso Comunidad indígena Yakye Axa Vs. Paraguay, 17 de junio de 2005, párr. 147, http://www.corteidh.or.cr/docs/casos/ articulos/seriec_125_esp.pdf. 
una alternativa al desarrollo), sino también la defensa de unas normas y de unas instituciones determinadas -las propias del Derecho indígena- que no se vean anuladas por la institucionalidad dominante. Estas ideas referidas permiten entender mejor el vínculo existente entre ambas reclamaciones: la diversidad en la manera de entender el desarrollo y, en consecuencia, la pluralidad a la hora de gestionarlo desde el punto de vista institucional y normativo. Y es ello lo que conduce a afirmar que el respeto a la jurisdicción y sistemas jurídicos de aquellos pueblos y nacionalidades indígenas que defienden sus territorios y modos de vida en armonía con la Naturaleza por parte del Estado permitiría mantener y/o fomentar alternativas sustancialmente diferentes o diametralmente opuestas al modelo de desarrollo convencional-economicista. Es decir, el establecimiento de un tipo de pluralismo jurídico fuerte ${ }^{5}$ legitimaría en condiciones de igualdad modos de vida otros y los sistemas jurídicos que los mantienen; todo lo cual fomentaría el avance hacia la superación del modelo de desarrollo convencional y de la doctrina jurídica monista.

Los movimientos de resistencia indígena han luchado por sus tierras y territorios y, por ello, se han disputado con el Estado y con las empresas transnacionales autorizadas por aquel el control de los mismos. El enfrentamiento entre estos diferentes agentes se debe a la pretensión de cada uno de ellos de ejercer su propia jurisdicción y, con ello, gobernar y gestionar este espacio y sus recursos de manera autónoma a partir de sus propios sistemas normativos. En el caso indígena dicha pretensión cuestiona el monismo jurídico del Estado y, por tanto, la legitimidad de la imposición del Derecho estatal a los territorios y personas indígenas que se guían por otro sistema jurídico y otras autoridades. Asimismo, cuestiona también la legitimidad de los permisos, planes y licencias que permiten que en sus territorios se les impongan actividades extractivas, empresariales, militares o de otra índole sin su autorización y sin la observancia debida a sus normas, medio y cultura. El respeto a la pluralidad y diversidad de los modos de vida indígenas no está garantizado en un contexto de dominio del Derecho estatal y por ello estos pueblos focalizan sus luchas contra el Estado y su doctrina jurídica monista, así como contra las empresas transnacionales y su pluralismo jurídico liberal-desarrollista. Puede observarse que, detrás de la pretensión de cada agente por el control jurídico de estos territorios y recursos, subyace una idea de modelo de vida y de sociedad, es decir, la disputa se enmarca en la perpetuación y profundización del modelo de desarrollo convencional domi-

5. Según John Griffiths, hay dos tipos de pluralismo jurídico: el pluralismo jurídico débil, que es una manifestación más de la doctrina jurídica monista por la cual los únicos derechos permitidos son los que reconoce el Estado, quien determina por cuestión de grupos, competencias, materias, etc., lo que puede ser conocido por normas diferentes a las propias del Estado y las que no. Y el pluralismo jurídico fuerte, que sostiene la igualdad jerárquica entre los diferentes sistemas jurídicos que coexisten, no siendo ninguno superior al otro. 
nante actualmente o en hacer valer otras lógicas y modelos alternativos a este, como se intenta en el caso - de entre otros- de los movimientos indígenas en la América Andina.

En conclusión, podemos sostener que la tradicional reivindicación territorial de los movimientos indígenas -aquellos que defienden la Naturaleza y sus modos de vida en armonía con esta- cuestiona precisamente el monismo jurídico imperante, asociado a la hegemonía del Estado-nación, y el modelo de desarrollo convencional depredador de recursos naturales y destructor de ecosistemas. A través de las reivindicaciones por hacer valer su derecho colectivo a sus tierras, territorios y recursos naturales, estos movimientos indígenas en defensa de la Naturaleza y de sus modos de vida se han opuesto al modelo de Estado monista y desarrollista dominante haciendo valer otras formas, otros modelos y, en definitiva, manteniendo la práctica concreta de alternativas al desarrollo. Con la promulgación de la Constitución de Montecristi este respeto a otras formas o modelos de vida parece haberse logrado al menos en el marco jurídico-político de referencia para el Estado y su actuar. Con esta Constitución un tipo de pluralismo jurídico entendido en clave posdesarrollista parece ser posible. Veamos en qué medida y por qué podría afirmarse esto.

\section{CONSTRUCCIÓN DEL PLURALISMO JURÍDICO POSDESARROLLISTA A PARTIR DE MONTECRISTI}

Antes de entrar en materia es necesario especificar qué entendemos por pluralismo jurídico posdesarrollista en este trabajo. Por pluralismo jurídico posdesarrollista consideraremos la legitimación en condiciones de igualdad con respecto al Derecho del Estado de los sistemas jurídicos indígenas y de las propuestas normativas de movimientos sociales de carácter emancipador. Se trata de una postura teórico-política que defiende una concepción amplia de Derecho y un tipo de pluralismo jurídico comunitario-participativo, según es entendido por Boaventura de Sousa Santos y Antonio Carlos Wolkmer. ${ }^{6}$ Apoya la pluralidad de sujetos capaces de producir y ejercer Derecho fuera de los límites impuestos por las instituciones jurídicas y de formación del Estado, así como otro tipo de procedimientos y autoridades que no responden a los cánones sostenidos por este. En este sentido es relevante entender que el pluralismo jurídico posdesarrollista no solo se opone al monismo jurídico

6. Boaventura de Sousa Santos, Sociología jurídica crítica: para un nuevo sentido común en el derecho (Madrid: Editorial Trotta / ILSA, 2009); y Antonio Carlos Wolkmer, Teoría crítica del Derecho desde América Latina (Bogotá: Akal, 2018). 
propio del Estado-nación moderno, sino también al modelo de desarrollo convencional-economicista en la medida en que hablamos de avalar sistemas jurídicos o propuestas normativas que defienden modos de vida que respetan y protegen la Naturaleza.

La defensa de que la construcción de un tipo de pluralismo jurídico entendido en clave posdesarrollista es posible en Ecuador viene dada por el estudio del articulado de la Constitución hoy vigente. En la Constitución de 2008 se reconocen los derechos colectivos de los pueblos indígenas, ${ }^{7}$ los derechos de la Naturaleza, ${ }^{8}$ los derechos del Buen Vivir ${ }^{9}$ y se declara que el Ecuador es un Estado de derechos, intercultural y plurinacional. ${ }^{10}$ La interpretación de esta categorización del Estado como un "Estado de derechos" (en plural) puede centrarse en la gran carga de derechos presentes en la Constitución, pero también como signo de la pluralidad de sistemas jurídicos que conforman el ordenamiento jurídico ecuatoriano, constituido por el Derecho del Estado y por una gran cantidad de sistemas jurídicos indígenas. ${ }^{11}$ Así, junto con el art. 167 y 171, el art. 1 ya nos indica que es un tipo de pluralismo jurídico fuerte el que avala la Constitución. No obstante, que a este pluralismo jurídico le coloquemos el adjetivo de "posdesarrollista" se debe a que dicho reconocimiento hay que incluirlo en un contexto más amplio de búsqueda del Sumak Kawsay/Buen Vivir, de protección de la Naturaleza y de construcción de un Estado intercultural y plurinacional.

El artículo 1, con toda su ristra de adjetivos, debe leerse como eje rector y guía interpretativo del conjunto de la Constitución, lo que supone que el total del articulado deba ser considerado y tratado bajo su foco. Por otro lado, debe considerarse que todos los derechos colectivos que le han sido reconocidos a los pueblos indígenas en el Capítulo Cuarto del Título II ${ }^{12}$ están regidos -como todos los demás derechos reconocidos- por las normas de aplicación generales estipuladas en el art. 11, que establece el mandato de directa e inmediata aplicación tanto de los derechos y garantías presentes en la Constitución como en los instrumentos internacionales de derechos humanos, en los que se encuentra -como se recordará- el Convenio n. ${ }^{\circ} 169$ de la Organización

7. Ecuador, Constitución de la República del Ecuador, Registro Oficial 449, 20 de octubre de 2008, Capítulo Cuarto del Título II, arts. 56-60.

8. Ibíd., Capítulo Séptimo del Título II, arts. 71-4.

9. Ibíd., Capítulo Segundo del Título II, arts. 12-34.

10. Ibíd., art. 1.

11. Ramiro Ávila Santamaría, El neoconstitucionalismo transformador: El Estado y el derecho en la Constitución de 2008 (Quito: Abya-Yala / Universidad Andina Simón Bolívar / Fundación Rosa Luxemburg, 2011), 121-34.

12. Ecuador, Constitución, arts. 56-60. 
Internacional del Trabajo (OIT) ${ }^{13}$ y la Declaración de los derechos de los pueblos indígenas de las Naciones Unidas. ${ }^{14} \mathrm{Y}$, además, la jurisprudencia de la Corte IDH en materia de derechos de los pueblos indígenas en virtud del art. 62 de la Convención Americana de derechos humanos, el cual establece la obligatoriedad de observancia para todos los Estados -y no solamente para el Estado implicado- de las sentencias de la Corte IDH ${ }^{15}$ relativas a la interpretación o a la aplicación de la Convención, como ha sido la interpretación del derecho de propiedad. ${ }^{16}$ Finalmente $-\mathrm{y}$ de gran relevancia- es la prohibición de que alguna norma jurídica venga a restringir dichos derechos o garantías. Todo ello significa que los sistemas jurídicos de pueblos y nacionalidades indígenas, así como sus modos de vida, están respaldados y avalados por la Ley Suprema del Estado llamada a guiar su actuar político y jurídico.

Más concretamente, la regulación del pluralismo jurídico y el reconocimiento explícito de la capacidad y legitimidad de los pueblos indígenas para aplicar sus propios sistemas jurídicos se encuentra en el Título IV de la Constitución relativa a la participación y organización del poder, concretamente en el Capítulo Cuarto, que viene a regular la Función Judicial y Justicia Indígena. ${ }^{17} \mathrm{Si}$ bien es cierto que el derecho de los pueblos indígenas a ejercer sus propios sistemas jurídicos viene ya determinado desde

13. OIT, Convenio 169 sobre pueblos indígenas y tribales. Aprobado en la Conferencia General de la Organización Internacional del Trabajo el 27 de junio de 1989, http://www.ohchr.org/SP/ProfessionalInterest/ Pages/Indigenous.aspx.

14. Naciones Unidas, Declaración de las Naciones Unidas sobre los derechos de los pueblos indígenas y tribales. Resolución 61/295 aprobada por la Asamblea General el 13 de septiembre de 2007, http://www. un.org/es/comun/docs/?symbol=A/RES/61/295. Fecha de consulta: 6 de marzo de 2017.

15. Corte IDH, "Sentencia de 15 de junio de 2005 (Excepciones Preliminares, Fondo, Reparaciones y Costas)", Caso de la Comunidad Moiwana Vs. Suriname, 15 de junio de 2005, http://www.corteidh.or.cr/ docs/casos/articulos/seriec_124_esp1.pdf; Corte IDH, "Sentencia de 17 de junio de 2005 (Fondo, Reparaciones y Costas)", Caso Comunidad indígena Yakye Axa Vs. Paraguay, 17 de junio de 2005, http://www. corteidh.or.cr/docs/casos/articulos/seriec_125_esp.pdf; Corte IDH, "Sentencia de 29 de marzo de 2006 (Fondo, Reparaciones y Costas)", Caso Comunidad Indigena Sawhoyamaxa Vs. Paraguay, 29 de marzo de 2006, http://www.corteidh.or.cr/docs/casos/articulos/seriec_146_esp2.pdf; Corte IDH, "Sentencia de 12 de agosto de 2008 (Interpretación de la sentencia de excepciones preliminares, Fondo, Reparaciones y Costas)", Caso del Pueblo Saramaka Vs. Surinam, de 12 de agosto de 2008, http://www.corteidh.or.cr/ docs/casos/articulos/seriec_185_esp.pdf; Corte IDH, "Sentencia de 24 de agosto de 2010 (Fondo, Reparaciones y Costas)", Caso Comunidad Indígena Xákmok Kásek Vs. Paraguay, 24 de agosto de 2010, http:// www.corteidh.or.cr/docs/casos/articulos/seriec_214_esp.pdf; Corte IDH, "Sentencia de 27 de junio de 2012 (Fondo y Reparaciones)", Pueblo Indigena Kichwa de Sarayaku Vs. Ecuador, 27 de junio de 2012, http://www.corteidh.or.cr/docs/casos/articulos/seriec_245_esp.pdf.

16. Esta tesis de aplicación del art. 62 de la Convención Americana sobre derechos humanos en lo relativo a los derechos territoriales de los pueblos indígenas ha sido sostenida por Mikel Berraondo, La protección de los territorios de los pueblos en aislamiento en América del Sur a partir del desarrollo de los derechos territoriales de los pueblos indígenas (tesis doctoral, Facultad de Derecho de la Universidad de Deusto, 2015).

17. Ecuador, Constitución, Capítulo Cuarto del Título IV, arts. 167-203. 
el art. 1 con la fórmula "Estado constitucional de derechos" y complementado por el art. 57 en su numeral 9 y 10, no es menos cierto que el Capítulo Cuarto del Título IV los refuerza considerablemente. Este refuerzo viene dado porque -si bien en Ecuador siempre ha habido pluralismo jurídico por la coexistencia de diversos sistemas jurídicos aparte del propio del Estado- no había sido reconocido antes de 2008 como un eje definitorio del modelo jurídico y político del Estado. En el art. 167 se reconoce que la potestad de administrar justicia se ejerce por los órganos de la Función Judicial (sistema jurídico ordinario) y por los otros órganos reconocidos en la Constitución (sistemas jurídicos indígenas). Ello significa que Derecho ordinario y Derecho indígena están en la misma posición jerárquica, ninguno por encima del otro y, por tanto, en teoría se estaría ante un tipo de pluralismo jurídico fuerte; un hito histórico en el que el monismo jurídico "cede" y deja lugar al pluralismo jurídico infraestatal propio de comunidades, pueblos y nacionalidades indígenas.

Asimismo, en el art. 171 se establece que "las autoridades de las comunidades, pueblos y nacionalidades indígenas ejercerán funciones jurisdiccionales, con base en sus tradiciones ancestrales y su derecho propio" y que dichas autoridades "aplicarán normas y procedimientos propios para la solución de sus conflictos internos, y que no sean contrarios a la Constitución y a los derechos humanos reconocidos en instrumentos internacionales". ${ }^{18}$ Esta salvedad de respeto a la Constitución y a los derechos humanos está también presente en el art. 21 y en el art. 57.10; límite al ejercicio del Derecho indígena que no representa grandes contrariedades si se considera que el control de respeto del mismo compete a la Corte Constitucional, competente para controlar que la justicia ordinaria haga lo propio y respete asimismo la Constitución y los instrumentos internacionales en materia de derechos humanos. Por otro lado, esta observancia de respeto a los derechos humanos como límite al ejercicio del Derecho indígena no tendría que representar mayores problemas desde una perspectiva decolonial y poscolonial siempre y cuando -y se subraya lo de siempre y cuando- se realice una interpretación intercultural de los derechos humanos y se tenga en consideración las reflexiones sobre la materia de autores como, entre otros, Boaventura de Sousa Santos, Joaquín Herrera-Flores, Felipe Gómez-Isa, Seyla Benhabid y Xavier Etxeberria. ${ }^{19}$

18. Ibíd., art. 171.

19. Santos, Sociología jurídica crítica, 509-41; Joaquín Herrera Flores, Los derechos humanos como productos culturales: critica del humanismo abstracto (Madrid: Los libros de la Catarata / IPES, 2005); Felipe Gómez Isa, "Diversidad cultural y derechos humanos desde los referentes cosmovisionales de los pueblos indígenas", Anuario Español de Derecho Internacional 27 (2011): 269-315; Seyla Benhabib, "Another Universalism: On the Unity and Diversity of Human Rights", American Philosophical Association 81, n. ${ }^{\circ} 2$ (2007): 7-32; y Xavier Etxeberria, "Derechos Humanos y Diversidad Cultural", en Los derechos 
Por otro lado, la alusión al "conflicto interno" del art. 171 puede ser entendido sin mayores dificultades - al no haber especificación en contrario- como todo conflicto que ocurra o afecte a territorios indígenas, ya venga causado por agentes internos o externos a nacionalidades, pueblos o comunidades. En este sentido, se entiende que cualquier proyecto de desarrollo o inversión en sus territorios -así como la militarización de los mismos por fuerzas del Estado- podría causar un "conflicto interno" en virtud del cual las nacionalidades, pueblos y comunidades indígenas estarían plenamente facultados por mandato constitucional a conocer y fallar ante dichos casos. Finalmente, siguiendo con el mandato presente en el mismo art. 171, el deber del Estado es garantizar que "las decisiones de la jurisdicción indígena sean respetadas por las instituciones y autoridades públicas". Este mandato tiene innumerables consecuencias según la opinión del profesor Trujillo ${ }^{20}$ que de entre ellas destaca que las decisiones de la autoridad indígena en el ejercicio de la función jurisdiccional son definitivas y que ningún órgano ordinario de justicia estatal puede revisarlas o incumplirlas. No obstante, las consecuencias que se derivan de dicho artículo no acaban aquí, y es que, según se sostiene en este trabajo, las decisiones de las autoridades indígenas en el ejercicio de su función jurisdiccional también abarcaría todo pronunciamiento sobre planes y proyectos de desarrollo en sus territorios. Ello supondría que el rechazo a dichos proyectos o planes tendría que ser respetado por el Estado y sus instituciones, así como por las empresas nacionales o transnacionales que quisieran operar en ellos.

Por otro lado, la participación de los pueblos y nacionalidades indígenas es otro de los elementos que debe considerarse en este punto. A los pueblos indígenas se les ha reconocido el derecho a participar en los organismos del Estado, en la definición de las políticas públicas, en el diseño de las prioridades del Estado y en ser consultados ante medidas legislativas que puedan afectarles. ${ }^{21}$ Asimismo, la Constitución establece de manera general que "la participación de la ciudadanía en todos los asuntos de interés público es un derecho, que se ejercerá a través de los mecanismos de la democracia representativa, directa y comunitaria". ${ }^{22}$ Aunque no se aporta ninguna definición sobre su alcance ni las posibles maneras de llevarla a cabo, se entiende -atendiendo al espíritu de la Constitución- que las discusiones y decisiones tomadas mediante la práctica de la democracia comunitaria deben ser respetadas y atendidas por el Estado y que,

indígenas tras la Declaración: el desafio de la implementación, ed. Felipe Gómez Isa y Mikel Berraondo (Bilbao: Universidad de Deusto, 2013), 39-61.

20. Julio César Trujillo, "Plurinacionalidad y Constitución", en Justicia indígena, plurinacionalidad e interculturalidad en Ecuador, ed. Boaventura de Sousa Santos y Agustín Grijalva Jiménez (Quito: Abya-Yala, 2013), 312.

21. Ecuador, Constitución, art. 57.15 y 57.16.

22. Ibíd., art. 95. 
por tanto, no se trata de cumplimentar ningún requisito ni acto formal. En este sentido, los pueblos y nacionalidades deben ser debidamente escuchados y consideradas sus aportaciones y críticas en todo punto legislativo y normativo que pueda afectarles.

Finalmente, es relevante indicar que el Estado ecuatoriano se reconoce como un Estado descentralizado. ${ }^{23} \mathrm{~A}$ este respecto, y en lo que interesa en relación con los derechos colectivos de los pueblos indígenas y a sus reivindicaciones históricas por el autogobierno de sus territorios, es importante considerar que en la Constitución se da la posibilidad de crear circunscripciones territoriales indígenas y pluriculturales como regímenes especiales. ${ }^{24} \mathrm{El}$ art. 257 establece que las circunscripciones indígenas o afroecuatorianas que pueden conformarse "ejercerán las competencias del gobierno territorial autónomo correspondiente, y se regirán por principios de interculturalidad, plurinacionalidad y de acuerdo con los derechos colectivos". ${ }^{25}$ No cabe duda de que la descentralización territorial favorecería el autogobierno y las posibilidades de que un territorio determinado fuera regido por las leyes propias del sistema jurídico indígena en cuestión y no por el Derecho estatal. Consideramos que la conformación de las circunscripciones territoriales indígenas podría ayudar en el autogobierno de estas comunas, comunidades, pueblos y nacionalidades y la puesta en práctica del tipo de pluralismo jurídico fuerte que avala la Constitución; tanto en lo correspondiente a la administración de justicia como en lo relativo al gobierno y regulación de los territorios conforme a leyes, instituciones, procedimientos y autoridades propias. La conformación de dichas circunscripciones permitiría un mejor ejercicio y garantía de los derechos colectivos indígenas reconocidos en la Constitución, facilitaría el autogobierno y posibilitaría un mejor y mayor control y gestión del territorio y de sus recursos; siendo las propias comunas, comunidades, pueblos y nacionalidades los actores que establecerían sus prioridades en las actividades socioeconómicas a realizar en sus territorios. Esto repercutiría notablemente en la conformación de un tipo de pluralismo jurídico entendido en clave posdesarrollista en la medida en que en muchas de estas circunscripciones - dada la existencia de notables y diversos modos de vida indígenas en armonía con la Naturaleza- se tendrían sustancialmente en cuenta el cuidado de los ecosistemas y sus ciclos naturales de reproducción. En estas se podría optar con menores presiones -dependiendo del nivel de autogobierno y las competencias- por actividades y modelos económicos que respetasen en gran medida los ciclos de reproducción de la vida y, en este sentido, sería más factible el andar hacia

23. Ibíd., art. 1.

24. Ibíd., arts. 242 y 60.

25. Ibíd., art. 257. Para la regulación legislativa de tales cuestiones hay que dirigirse a Ecuador, Código Orgánico de Organización Territorial, Autonomía y Descentralización, Registro Oficial Suplemento 303, 19 de octubre de 2010. 
transformaciones que superasen el modelo de desarrollo convencional economicista y extractivista que impera y/o que intenta imponerse. ${ }^{26}$

En definitiva, el conjunto del articulado aquí referido avala y respalda la capacidad de los pueblos y nacionalidades de organizar y gestionar sus territorios conforme a sus propias leyes, instituciones, autoridades y procedimientos. La presencia de este articulado en la Constitución, sin olvidar que deben leerse bajo el foco del marco general de búsqueda del Buen Vivir/Sumak Kawsay, protección de los derechos de la Naturaleza y definición del Estado como intercultural y plurinacional, ampara y protege en el marco jurídico-político del Estado ecuatoriano modos de vida diversos; modos de vida alternativos al modelo de desarrollo convencional-economicista y estas otras legalidades o sistemas jurídicos que los hacen posibles. Sin embargo, estas posibilidades de avance hacia la superación de la doctrina jurídica monista y del modelo de desarrollo convencional del texto constitucional chocan con no pocos límites; límites, tensiones y contradicciones que se encuentran comprendidos entre el propio articulado y que se manifiestan de muy diferentes maneras en la práctica del Estado.

Algunos de los principales límites o tensiones que encontramos dentro del texto Constitucional es la falta de cambios o transformaciones en la organización del poder y de la estructura del Estado. ${ }^{27}$ Se considera preocupante el hecho de que no hayan cupos obligatorios de representatividad de los pueblos y nacionalidades en los diferentes poderes del Estado y que, en concreto, no se haya valorado dicho cupo en un órgano tan relevante como la Corte Constitucional, órgano común de las dos justicias. También es sumamente contradictorio que la propiedad de los recursos naturales no-renovables sea del Estado sin importar que estos se encuentren en territorios ancestrales de pueblos y nacionalidades o no. Y que, por otro lado, no se haya reconocido el derecho colectivo a la consulta vinculante o consentimiento y que, tampoco, se haya incluido el término de autodeterminación de los pueblos y nacionalidades. Asimismo, es una

26. El Código Orgánico de Organización Territorial, Autonomía y Descentralización no está libre de fuertes críticas por parte de los movimientos de los pueblos indígenas, y ello debido principalmente a que el proceso de conformación de estas circunscripciones no se realiza conforme a los propios sistemas jurídicos indígenas ni, concretamente, siguiendo sus parámetros y mecanismos en lo relativo a sus procesos en la toma de decisiones. En este sentido este Código es una norma creada bajo el paradigma del Derecho estatal y como tal no ha respetado el mandato constitucional que instaura la pluralidad jurídica en Ecuador, ya que se le ha dado prevalencia y mayor importancia a la hora de regular y ordenar el territorio al sistema jurídico estatal o -si se prefiere- al Derecho ordinario. Para consultar críticas relativas a las circunscripciones territoriales indígenas, ver Pablo Ospina Peralta, "Estado plurinacional y autogobierno territorial: Demandas indígenas en Ecuador", en La autonomía a debate: Autogobierno indígena y Estado plurinacional en América Latina, coord. Miguel González, Araceli Burguete Cal y Mayor y Pablo Ortiz-T. Quito (Quito: FLACSO, 2010), 201-18.

27. Roberto Gargarella, "La 'sala de máquinas' de las constituciones latinoamericanas: entre lo viejo y lo nuevo", Nueva Sociedad 257 (2015): 96-106. 
tensión latente dentro del articulado la opción entre una alternativa al desarrollo (legitimidad de modos de vida diversos en armonía con la Naturaleza) y una alternativa de desarrollo (profundización del modelo de desarrollo convencional-economicista o el llamado neodesarrollismo). En conclusión, la Constitución de Montecristi puede ser interpretada desde una perspectiva posdesarrollista (en la que se enfatiza las posibilidades de superación del modelo desarrollista y monista) o desarrollista (en la que se incide en las posibilidades de seguir mercantilizando la vida y los recursos naturales). Es la primera de ellas la que posibilitaría cambios estructurales conducentes a transformaciones radicales que permitirían la diversidad de modos de vida y, en definitiva, que los pueblos indígenas que mantienen y defienden modos de vida en armonía con la Naturaleza pudiesen seguir manteniéndolos sin la amenaza constante del expolio posibilitado por el Derecho estatal que sostiene un modelo de desarrollo convencional-economicista que devasta culturas y ecosistemas.

\section{CONCLUSIONES}

Pese a todo, puede afirmarse que la lectura conjunta de todos los artículos enunciados aporta razones suficientes para sostener que dentro de sus territorios las naciones, pueblos, comunidades y comunas indígenas podrían materializar sus formas de convivencia y de organización socioeconómica conforme a su Derecho propio, lo cual incluye instituciones, procedimientos y autoridades. Ello permite hablar de un tipo de pluralismo jurídico fuerte (infraestatal) que debe ser interpretado junto con el reconocimiento de los derechos de la Naturaleza y la búsqueda del Sumak Kawsay dentro de un Estado plurinacional e intercultural; todo lo cual debería -en teoría y con el respaldo de todo el articulado referido- permitir que en territorios indígenas pudiesen mantenerse modos de vida en armonía con la Naturaleza; modos de vida que -evidentemente por sus características- son diametralmente opuestos o sustancialmente diferentes al modelo de desarrollo convencional-economicista. Precisamente en esta posibilidad abierta por la Constitución de Montecristi reside su potencial capacidad transformadora.

Y es que todo ello significa que -de respetarse y llevarse a la práctica los artículos constitucionales señalados- muchas comunidades y pueblos indígenas en resistencia podrían decidir y gestionar libremente conforme a sus derechos la utilización y futuro de sus territorios y de las actividades económicas que en ellos se desarrollen. Como se intuirá, ello podría abrir la puerta a la construcción del tránsito del modelo de desarrollo convencional a otras alternativas de vida en muchos territorios o, en numerosos casos, impedir la entrada de dicho modelo a zonas donde aún los modos de vida son diversos y conviven de una forma más armónica con la Naturaleza y sus ciclos. 
La Constitución de Montecristi no está libre de tensiones y contradicciones que pueden mermar esta capacidad transformadora de superación del modelo desarrollista y monista imperante, pero lo cierto es que hay suficiente respaldo jurídico y político en su articulado para enfatizar su potencial emancipador. En este trabajo, precisamente, se ha pretendido subrayar dicho potencial e intentar llamar la atención sobre las posibilidades de transformación que existen en la Constitución ecuatoriana de 2008 para superar el modelo de desarrollo convencional y la doctrina jurídica monista que devasta culturas y ecosistemas. Los límites y contradicciones presentes en la Constitución y en las prácticas y actos del Estado que pueden impedir el avance hacia un tipo de pluralismo jurídico posdesarrollista son un hecho, no se ignoran, pero su estudio ameritaría un análisis que en esta ocasión supera el objeto del presente trabajo y los límites de espacio del que se dispone. Queda, por tanto, pendiente este estudio; no obstante, y por ahora, se invita a reflexionar sobre este potencial transformador $-\mathrm{O}$ si se prefiere, emancipador- de la Constitución de Montecristi en los términos aquí planteados: las posibilidades existentes en el articulado constitucional para avanzar hacia la construcción de un tipo de pluralismo jurídico entendido en clave posdesarrollista que legitime modos de vidas otros y los sistemas jurídicos que los regulan y mantienen.

\section{BIBLIOGRAFÍA}

Ávila Santamaría, Ramiro. El neoconstitucionalismo transformador: El Estado y el derecho en la Constitución de 2008. Quito: Abya-Yala / Universidad Andina Simón Bolívar / Fundación Rosa Luxemburg, 2011.

Benhabib, Seyla. "Another Universalism: On the Unity and Diversity of Human Rights". American Philosophical Association 81, n. ${ }^{\circ} 2$ (2007): 7-32.

Berraondo, Mikel. La protección de los territorios de los pueblos en aislamiento en América del Sur a partir del desarrollo de los derechos territoriales de los pueblos indigenas. Tesis doctoral, Facultad de Derecho de la Universidad de Deusto, 2015.

Corte IDH. "Sentencia de 15 de junio de 2005 (Excepciones Preliminares, Fondo, Reparaciones y Costas)". Caso de la Comunidad Moiwana Vs. Suriname. 15 de junio de 2005. http:// www.corteidh.or.cr/docs/casos/articulos/seriec_124_esp1.pdf.

—. "Sentencia de 17 de junio de 2005 (Fondo, Reparaciones y Costas)". Caso Comunidad indigena Yakye Axa Vs. Paraguay. 17 de junio de 2005. http://www.corteidh.or.cr/docs/ casos/articulos/seriec_125_esp.pdf.

- "Sentencia de 29 de marzo de 2006 (Fondo, Reparaciones y Costas)". Caso Comunidad Indigena Sawhoyamaxa Vs. Paraguay. 29 de marzo de 2006. http://www.corteidh.or.cr/ docs/casos/articulos/seriec_146_esp2.pdf. 
—. "Sentencia de 12 de agosto de 2008 (Interpretación de la sentencia de excepciones preliminares, Fondo, Reparaciones y Costas)". Caso del Pueblo Saramaka Vs. Surinam. 12 de agosto de 2008. http://www.corteidh.or.cr/docs/casos/articulos/seriec_185_esp.pdf.

—. "Sentencia de 24 de agosto de 2010 (Fondo, Reparaciones y Costas)". Caso Comunidad Indígena Xákmok Kásek Vs. Paraguay. 24 de agosto de 2010. http://www.corteidh.or.cr/ docs/casos/articulos/seriec_214_esp.pdf.

- "Sentencia de 27 de junio de 2012 (Fondo y Reparaciones)". Pueblo Indígena Kichwa de Sarayaku Vs. Ecuador. 27 de junio de 2012. http://www.corteidh.or.cr/docs/casos/articulos/seriec_245_esp.pdf.

Ecuador. Código Orgánico de Organización Territorial, Autonomía y Descentralización. Registro Oficial Suplemento 303, 19 de octubre de 2010.

-. Constitución de la República del Ecuador. Registro Oficial 449, 20 de octubre de 2008.

Etxeberria, Xavier. "Derechos Humanos y Diversidad Cultural”. En Los derechos indígenas tras la Declaración: el desafio de la implementación, editado por Felipe Gómez Isa y Mikel Berraondo, 39-61. Bilbao: Universidad de Deusto, 2013.

Gargarella, Roberto. La "sala de máquinas" de las constituciones latinoamericanas: entre lo viejo y lo nuevo. Nueva Sociedad 257 (2015): 96-106.

Gómez-Isa, Felipe. "Diversidad cultural y derechos humanos desde los referentes cosmovisionales de los pueblos indígenas". Anuario Español de Derecho Internacional 27 (2011): 269-315.

Griffiths, John. "What is Legal Pluralism?". Legal Pluralism \& Unofficial Law 18, n. ${ }^{\circ} 24$ (1986): 1-55.

Herrera-Flores, Joaquín. Los derechos humanos como productos culturales: crítica del humanismo abstracto. Madrid: Los libros de la Catarata / IPES, 2005.

Lang, Miriam. ¿Erradicar la pobreza o empobrecer las alternativas? Quito: Universidad Andina Simón Bolívar / Abya-Yala, 2017.

Merry, Sally Engle. "Legal Pluralism”. En Social Control: Aspects of Non-state Justice, editado por Stuart Henry, 137-64. The International Library of Criminology and Criminal Justice. England: Dartmouth, 1994.

Naciones Unidas. Declaración de las Naciones Unidas sobre los derechos de los pueblos indígenas y tribales. Resolución 61/295 aprobada por la Asamblea General el 13 de septiembre de 2007. http://www.un.org/es/comun/docs/?symbol=A/RES/61/295.

OIT, Organización Internacional del Trabajo, Convenio $n .{ }^{\circ} 169$ sobre pueblos indigenas y tribales. Aprobado en la Conferencia General de la Organización Internacional del Trabajo el 27 de junio de 1989. http://www.ohchr.org/SP/ProfessionalInterest/Pages/Indigenous.aspx.

Ospina-Peralta, Pablo. "Estado plurinacional y autogobierno territorial: Demandas indígenas en Ecuador". En La autonomía a debate: Autogobierno indigena y Estado plurinacional en América Latina, coordinado por Miguel González, Araceli Burguete Cal y Mayor y Pablo Ortiz-T., 201-18. Quito: FLACSO, 2010. 
Santos, Boaventura de Sousa. "Law: A Map of Misreading: Toward a Postmodern Conception of Law". Journal of Law and Society 14, n. 3 (1987): 279-302.

- Sociología jurídica crítica: para un nuevo sentido común en el derecho. Madrid: Trotta / Ilsa, 2009.

Tamanaha, Brian Z. "A Non-Essentialist Version of Legal Pluralism”. Journal of Law and Society 27, n. 2 (2000): 296-321.

Trujillo, Julio César. "Plurinacionalidad y Constitución”. En Justicia indígena, plurinacionalidad e interculturalidad en Ecuador, editado por Boaventura de Sousa Santos y Agustín Grijalva Jiménez, 305-14. Quito: Abya-Yala, 2013.

Wolkmer, Antonio Carlos. Pluralismo jurídico: Fundamentos de una nueva cultura del Derecho. Sevilla: MAD, 2006.

—. Teoría crítica del Derecho desde América Latina. Bogotá: Akal, 2018.

Yrigoyen Fajardo, Raquel. Pautas de Coordinación entre el Derecho Indígena y el Derecho Estatal. Ciudad de Guatemala: Fundación Myrna Mack, 1999. 